\title{
Challenges of Implementing a Performance and Reward System in Higher Education Institutions in Pakistan: Perceptions of Top Leaders in Contending Regulatory Bodies
}

\author{
Tayyeb Ali Khan ${ }^{1} \cdot$ Tom Christensen ${ }^{2}$
}

Accepted: 16 September 2020 /Published online: 1 October 2020

(C) The Author(s) 2020

\begin{abstract}
This article is a study of the challenges of implementing a performance and rewards management system for academics (Tenure Track System - TTS) in Pakistan over the last decade. The main empirical focus is on the perceptions of the leading implementer, the Higher Education Commission (HEC). These are supplemented by the perceptions of the Provincial Higher Education Commission (PHEC) in Punjab. Semi-structured interviews and document analysis were the two methods used to collect data. The study is based on two perspectives from organizational theory, a structural and a cultural perspective. The main findings highlight how leaders implemented TTS despite its incompatibility with the structure and culture of public universities in Pakistan. The study also revealed tensions between two reward systems - BPS and TTS - as well as the effects of the 18th constitutional amendment on the implementation of higher education programs. This study contributes insights into the reform of the higher education system in developing countries in the context of NPM.
\end{abstract}

Keywords Higher education reform · Tenure track system (TTS) - Basic pay scale (BPS) . Implementation · Pakistan

Tom Christensen

tom.christensen@stv.uio.no

Tayyeb Ali Khan

Tayyeb.ias@pu.edu.pk

1 Institute of Administrative Sciences, University of the Punjab, Lahore, Pakistan

2 Department of Political Science, University of Oslo, Oslo, Norway 


\section{Introduction}

Over the last three decades many countries around the world have adopted and attempted to implement public sector reforms (Pollitt and Bouckaert 2017). In the two waves of reform known as New Public Management (NPM) and post-NPM, there has been some debate about whether these waves represent global convergence, following certain generic principles, or whether countries have followed divergent paths stemming from their specific structural and cultural features (Tight 2007). The NPM reforms started in the early 1980s and were based on a mixture of new institutional economic theory and management theories. They focused on devolution, efficiency, performance management, use of markets and service-orientation (Christensen and Lægreid 2007).

Post-NPM reforms emerged in the late 1990s as a reaction to NPM. They did not replace it, however, but introduced a renewed focus on centralization, more vertical and horizontal coordination, and cultural integration. Since then, public-sector reforms around the world have been a complex and hybrid mixture of these two reform waves, resulting in multi-layered forms of public organization (cf. Mahoney and Thelen 2010).

Globally, higher education reforms have followed the same main trajectory as public-sector reforms, but with a wide variety of single reform elements that do not always fit together (Beerkens 2003; Cantwell and Maldonado-Maldonado 2009; Ferlie et al. 2008; Krücken 2014; Tierney 2014). Global processes of rationalization and standardization have turned universities into formal organizations that resemble any other public-sector organization (Beerkens 2003). This is the result partly of increased social embeddedness and partly of increased use of modern market and management principles (Christensen et al. 2019).

Universities are now less communities of scholars and more a part of the knowledge economy (Olsen 2009). They are more integrated into national and global markets of researchers, research projects and students, as reflected in a greater focus on international rankings and incentive systems for researchers (Ramirez and Christensen 2013). The universities have also become more democratic, weakening the traditional dominance of the professors, while university administrations have grown and become more professional and influential in response both to internal growth and to increased complexity (Paradeise et al. 2009). Increased external embeddedness means having a closer relationship with superior national authorities and paying more attention to their planning and reporting requirements, but also to resource-generating external private stakeholders.

Many countries underwent a series of reforms in the last quarter of the twentieth century. In many cases, these reforms were influenced by New Public Management. This study is one of a series of studies that have highlighted the challenges of implementing performance and reward management systems for academics in the context of NPM. Numerous studies have identified tensions and problems during the implementation of US-based tenure track in Europe (Henningsson et al. 2018; Pietilä 2017; Degn 2014) and several of them have focused on the response of university leaders to NPM-style reforms in the public sector and notably in higher education (Huang et al. 2016; Kohtamäki 2018; Jeanes et al. 2018). Many studies have elaborated on the challenges of academic performance management (Söderlind and Geschwind 2019; Pietilä 2015) and elucidated the complexities of that process in the public sector 
context (Butler 2019; Ma and Christensen 2018; Pashiardis and Brauckmann 2018). Some studies have been conducted to identify the challenges of implementing higher education reforms in developing countries (Gaus et al. 2018, Harun et al. 2019; Mohammadi and Mirzamohammadi 2019.), and how leaders have responded to these challenges (Degn 2014; Söderlind and Geschwind 2019). Therefore, the topic of performance and reward management in the context of NPM is relevant in the recent literature on public management reforms, notably in higher education.

This article focuses on a specific higher education reform in Pakistan that started in 2005 and is still ongoing, namely, the Tenure-Track System (TTS) (Khan and Nasira 2011). This system originated in the US and has a long history in the West, but it is increasingly coming under pressure following the introduction of a system of shorter contracts for professors. Developing countries often imitate public reforms adopted by other countries - usually with a time lag - either as a result of pressure from international organizations or because they are actively seeking new solutions (Pollitt and Bouckaert 2017). This raises the challenge of adapting such reforms to national structures and cultures.

During the nearly two hundred years that the Indo-Pak sub-continent was under British rule, the higher education system there had problems of cultural sustainability. In the post-colonial era, the British system has been partly replaced by a higher education system based on an American template. As a result, Pakistan's higher education institutions became an amalgamation of the UK and the US models, which made the sector more complex and hybrid (cf. Ramirez and Christensen 2013). When global reforms took place in higher education over the last few decades, Pakistan often lagged behind, without necessarily having the benefit of learning from experience.

Pakistan's higher education institutions, especially the newer public universities, have relied heavily on financial resources from both the federal and provincial governments, potentially creating tensions and conflicts between the two levels. The Higher Education Commission (HEC) of Pakistan, a regulatory body, has launched several initiatives to reform higher education institutions, often inspired by NPM. The Tenure-Track System (TTS) was one of these reforms (a system where academic faculty join the scheme is referred to as Tenure-Track Faculty - TTF). We focus on the role of the HEC in the implementation of this reform, primarily the perceptions of its leaders. We also analyze the perceptions of the leaders of the provincial equivalent of the HEC, the Provincial Higher Education Commission (PHEC), in order to get a critical view of the role of the HEC. PHEC leaders are struggling to make their existence relevant in the sector, but the role of PHEC is evolving and its presence is felt in public universities. The divergence between its leaders' perspectives and those of HEC leaders is interesting and will affect policy formulation and implementation in higher education institutions in Pakistan. It is worth pointing out here that the leaders of the HEC and the PHEC have not agreed on how responsibilities should be allocated between them.

Our research questions in the study are accordingly:

- How did the leaders of HEC experience and perceive the challenges associated with implementing the TTS in public universities in Pakistan?

- How did these perceptions align with the views of the leaders of PHEC, and how did they diverge? 
- How can one analyze the TTS reform challenges, as seen by the leaders of the HEC and the PHEC, using structural and cultural perspectives from organization theory?

As stated, the theoretical basis for the analysis is two organization theory perspectives an instrumental and a cultural one (Christensen et al. 2020). The data for this research comes from semi-structured interviews with the leaderships of both regulatory bodies.

The study starts by outlining the theoretical perspectives and then explains the context of the Pakistani higher education system and TTS. It then describes and analyzes the main challenges of the implementation process, as seen by the leaders of the regulatory bodies.

\section{Theory - How to Explain the Challenges of Reform Implementation?}

The instrumental perspective belongs to the logic of consequence and bounded rationality (March 1994; Simon 1957), while the cultural one belongs to institutional theories and the logic of appropriateness (Christensen et al. 2020; Selznick 1957). The instrumental perspective stresses that the conscious structural design of public organizations by political and administrative leaders is crucial for achieving public goals, i.e. in our case to implement and bring into effect a higher education reform (cf. Egeberg 2014). Therefore, reforms represent changing goals, often reflected in structural changes, in our case, changes in career structure, which, in turn, presumably result in changes in actors' behavior - i.e. in professors producing more and better research. The perspectives come in two versions - a hierarchical and a negotiational one (March and Olsen 1983). The first emphasizes that top leaders in public organizations are most important when reforms are being implemented (Patashnik 2014). The second presupposes that public organizations are heterogeneous, comprising actors with different interests and different definitions of problems and solutions.

A reform is strongly related to the governance capacity of public organizations, meaning the resources and competencies available. According to Lodge and Wegrich (2014), this capacity can be one of four types. Analytical capacity is about the ability to define goals, problems, solutions and expected effects of different structural options. Coordination capacity is about whether leaders can coordinate decision-making and come up with solutions to complex problems, in our case to get the HEC and public universities to collaborate. Regulation capacity is about the ability of the government to constrain and control, in our case to create a regulatory regime for the new TTS. Finally, delivery capacity concerns the ability to implement and to make plans a reality, in our case to implement TTS.

An instrumental perspective on TTS as a university reform would, according to the hierarchical version, focus on the perceptions of the top leaders, in our case the leaders of the regulatory body, the Higher Education Commission, and analyze their capacity and efforts to control the process and to implement TTS as well as the challenges they encountered. The negotiation version implies looking at disagreements among the top leaders, whether in the HEC or the PHEC, and the challenges generated by different interests in the universities in question. 
The cultural perspective, based on Selznick (1957), would see public organizations in our case universities - through the prism of informal norms that have evolved through mutual adaptation to internal and external pressure, resulting in a unique identity specific to each institution. Path-dependency means that cultural roots are important for the future path taken (March 1994). When reforms are proposed, cultural compatibility will be essential (Brunsson and Olsen 1993). Kingdon (1984) elaborates on this theory and proposes that breaks in the historical trajectory and embarking on a new track, like TTS, happens when entrepreneurs utilize windows of opportunity.

Using such a perspective on university reforms, we will focus on whether the top leaders' imagined or actually experienced cultural resistance when implementing the reform and what factors this possible resistance was connected with. In addition, we ask whether the leaders and the universities saw TTS as a break in the historical trajectory.

This article is an essential contribution to the study of the implementation of reform in the higher education system of Pakistan - one of the largest developing countries. This study represents independent research, which may potentially make a significant contribution to the field of public management reforms, particularly those in higher education management. The research questions are essential from a theoretical and practical point of view. This study provides new insights into the conditions for implementing an active reform policy and into the reform of universities in Pakistan. One of the significant contributions of this paper to the academic literature and policymaking is to show how leaders met the challenge of implementing NPM principles at the regional level.

\section{Context}

There are three regulatory actors in the province of Punjab and Sindh - the main actor HEC at the federal level, the PHEC at the provincial level ${ }^{1}$ and the Higher Education Department (HED) ${ }^{2}$ working under the provincial education ministry. The HEC was established in $2002^{3}$ to improve Pakistan's higher education sector. The HEC's head office is located in Islamabad and it has four regional offices located in Lahore, Karachi, Quetta, and Peshawar. The HEC is governed by an appointed chairman and reports directly to the Chief Executive of Pakistan. The HEC is an autonomous body and is not subordinate to the Ministry of Education. The governing body of the HEC is called the commission and has sixteen members. The executive director is ex officio secretary of the commission. ${ }^{4}$ The PHEC is an autonomous body headed by the chairperson, who is appointed by the Chief Minister of Punjab.

Public universities in Pakistan are part of and mostly financed by the federalprovincial government. They use the Basic Pay Scale (BPS), which is the traditional public pay system and has been adapted to public universities and linked to the national pay scales of public officials. TTS, implemented from $2003^{5}$ on, was a new pay system for academic faculty at the universities. The release of funds for salaries started in the

\footnotetext{
${ }^{1}$ http://punjabhec.gov.pk/about-phec

${ }^{2}$ https://hed.punjab.gov.pk/

${ }^{3}$ https://www.hec.gov.pk/english/aboutus/Documents/455_HECOrdinance.pdf

${ }^{4}$ https://www.hec.gov.pk/english/aboutus/Documents/455_HECOrdinance.pdf\#search=executive\% 20director

${ }^{5}$ The letter from Chairman HEC to Vice Chancellors of public universities of Pakistan.
} 
financial year 2005-06. ${ }^{6}$ TTS is a better salary package than $\mathrm{BPS}^{7}$; for instance, a professor's salary under TTS was initially almost four times higher than a professor's salary under BPS. ${ }^{8}$

The tenure-track statutes that HEC introduced in $2008^{9}$ stated that 'tenure' was intended (i) to promote freedom of teaching and of extramural activities and (ii) to provide sufficient economic security to make the profession attractive to able men and women. This was a limited definition of the purpose of tenure and lacked a causal link between the granting of tenure and achieving teaching excellence and economic security. The explicit goal of introducing TTS was evidently to promote academic freedom and financial security.

The Higher Education Commission (HEC) had endorsed 2984 cases of academic staff being hired under TTS as of June 30, 2018. ${ }^{10}$ There were 35,809 permanent faculty members in Pakistan's public universities in 2017-18. ${ }^{11}$ TTS faculty members make up about $8 \%$ of permanent faculty members, and that figure has not changed for seven years. If adjunct and part-time faculty, which is an increasing category, are counted as well, this percentage is even lower.

The majority of TTS faculty members (85\%) belong to sciences and engineering disciplines, while a small number (15\%) come from the social sciences, humanities and management sciences. The majority of TTS faculty members are assistant professors $(91 \%)$. The share of associate professors and full professors is $4 \%$ and $5 \%$ respectively in 78 higher education institutions of Pakistan as of 2018. TTS is concentrated in a few higher education institutions. COMSATS University Islamabad has the highest number of TTS faculty members (25\%) of all higher education institutions. ${ }^{12}$ There has been a decrease in the new introduction of TTS, and it can be inferred that TTS is moving forward at a snail's pace in Pakistan's higher education institutions.

\section{Method}

The study uses a multiple case study design to describe the content, processes, and implementation of a higher education reform. The study is qualitative and focuses on the experiences of the top leadership of the HEC and the PHEC with a primary focus on TTS. The leaders of the HEC are the main significant actors in initiating, developing, and executing higher education reform programs. The leaders of HEC who responded represent different timelines of the program, some of them having launched the change process and others currently leading the HEC (see appendix Table 2). The PHEC is a newly formed regulatory body at the provincial level, and PHEC leaders were not

\footnotetext{
${ }^{6}$ Higher Education Commission report on Tenure Track Funds Released to Universities / Institutes / Centres (FYs 2005-06 to 2013-14.

${ }^{7}$ www.civilservicerules.com

${ }^{8} \mathrm{http} / /$ hec.gov.pk/english/services/universities/FP/Documents/Revised\%20TTS\%20Salary\%20Package\% 202015. pdf

${ }^{9}$ https://www.hec.gov.pk/english/services/universities/tts/Documents/Model\%20TTS\%20Ver\%202\%200\% 20\%2805-07-12\%29.pdf (page 10)

${ }^{10} \mathrm{http} / /$ hec.gov.pk/english/services/universities/tts/Documents/List\%20of\%20Endorsed\%20TTS\% 20Faculty\%20Mmmbers.pdf.

${ }^{11}$ These numbers were estimated based on assumed annual growth of 10\%. The base year was 2014-15.

${ }^{12} \mathrm{http} / /$ hec.gov.pk/english/services/universities/FP/Pages/TTS-Faculty.aspx
} 
actively involved in the reform process. However, they have observed the implementation of HEC policies over the last three years and thus function as a 'critical' group of observers in the study. One leader from the PHEC also worked at the HEC for many years.

The study uses multiple data sources and includes primary data collection methods: face to face interviews, and Skype and telephone interviews. However, secondary sources of information are also used, including public documents and reports about higher education reforms in Pakistan, the TTS program and HEC's written correspondence with universities.

Semi-structured interviews asking participants to elucidate their experience with reform processes were the primary source of information. The participants were asked the same questions to ensure consistency and comparability of data. However, the leaders of the HEC were probed to elaborate their critical observations about how higher education institutions had responded to the implementation of reforms. The interviews covered a wide range of topics such as resistance from public universities, governance, management and autonomy of public universities, the role of the HEC in implementing higher education reforms, dual rewards systems, the effects of TTS on higher education institutions, the role of the HEC in implementing higher education reforms, etc.

We sought consent from the heads of the commissions for their participation in the study. The interviews with the seven respondents (see appendix Table 2) lasted between 40 and $80 \mathrm{~min}$ and were recorded with the consent of interviewees and transcribed verbatim. The following titles were considered elite actors for this research study: Chairman, Executive Director, Director, and Adviser Quality Assessor. The data were analyzed using a combination of qualitative content analysis, interpretive phenomenological analysis, and thematic analysis. Interpretive phenomenological analysis was applied to individual cases; thematic analysis and pattern analysis were used to assimilate common themes. Qualitative content analysis was used on common themes to collate the results of each case study.

\section{Main Results}

The main aim of the study was to elaborate on the challenges of implementing TTS in Pakistan, as perceived by the leaders of the central regulatory bodies and to ascertain what role they played in reform outcomes. This section is divided into two case studies, one looking at the experiences and perceptions of top leaders of the HEC, and the second and supplementary one looking at how top leaders of the PHEC saw the challenges the HEC encountered in implementing the reform.

\section{The Case of the Higher Education Commission}

The following themes emerged from the analysis of semi-structured interviews with the HEC leaders and the documents. 
Structural and Cultural Challenges for the HEC in Implementing TTS Organizationally, the HEC did not focus on enhancing the capacity of the Registrar's ${ }^{13}$ office to implement TTS. The HEC left it to the Vice-Chancellor and the Registrar to implement the new system at the universities based on their understanding of TTS. Consequently, inconsistencies and variations occurred both within each university and across different universities, because of cross-level and internal university heterogeneity, tensions, and disagreements.

The final approval of all performance and reward-related cases under TTS lies with the management of the HEC, meaning that the reform was extremely centralized. However, owing to staff shortages at HEC, there were delays in processing the cases of TTS faculty. One leader explained, 'I have just two persons who were looking after all the cases of TTS, so I was not able to provide you with the data. We were short of staff; that was why it was not possible for us to answer individual emails of the faculty' (Case HEC: Respondent 1). The HEC staff has a checklist of criteria against which to evaluate all cases, and the focus of the evaluation was narrowed down to research papers. This made the evaluation process slightly different from the peer evaluation of tenure in US universities, which is a much more elaborate and locally based process. HEC leaders did not decentralize the system, since they wanted to ensure standard criteria, transparency and merit for performance evaluation of TTS faculty members and to free this evaluation from the politicized culture of the public universities. However, the capacity and skills of HEC staff to process TTS faculty in all public universities in Pakistan remain questionable, and indeed, the volume of work resulted in an overburdening of HEC staff and frustration among TTS faculty due to delays in processing. The HEC could have devolved this function to public universities or recruited trained staff to process cases, but this did not happen.

Effective implementation of the Tenure-Track System required timely decisions on all cases of TTS. There were procedural delays both at universities and at the HEC level, which slowed down the implementation of TTS. Faculty members on TTS complained about the HEC's failure to respond. The team that had introduced the HEC reforms left the HEC, with a resulting loss of institutional memory and knowledge and hence a slowing of the momentum for implementation of the reform, especially following the resignation of the chairman of HEC in 2008. The latter had been the main driver of the reform process and had built the foundations for higher education reforms over a period of six years. In addition, the lack of financial support from the new government slowed down the whole process of change. This change in power and network structure paved the way for the formation of provincial higher education commissions, which further weakened the power of the federal HEC. One leader said: 'If these setups of multiple higher education commissions continue, then disaster will happen. Because you have a multiplicity of standards for institutions and degrees, there will be major chaos, and I was fighting it out to prevent this from happening' (Case HEC: Respondent 1).

Separating the governance and management of public universities proved problematic, with politicians seeking to interfere in the administrative matters of public

\footnotetext{
${ }^{13}$ The Registrar shall be in charge of the entire administration of the University and all matters relating to it shall be forwarded to him who will obtain orders of the Vice-Chancellor whenever necessary. http:/pu.edu. pk/ images/ file/PU-Calendar-Vol-I/15-Part-XIII-(735-760).pdf. Page 752
} 
universities, but this was not initially realized. After the 18th constitutional amendment, provincial governments established the Provincial HEC. Clear jurisdictions of the Federal HEC and the Provincial HEC were not established, and another layer of regulation at the provincial level further curtailed the real autonomy of public universities, not to mention the confusion and tension related to their overlapping roles.

One leader said the following about the impact of the 18th amendment on higher education institutions: 'Government did not spend time understanding the impact of the 18 th amendment on the education sector. Our politicians were interested in direct control of universities while they were supposed to create laws, policies and framework' (Case HEC: Respondent 2). Another leader said: 'If there were coordination and synergy between the federal and provincial HEC, then this was good for higher education. They should work in consultation with each other, not against each other' (Case HEC: Respondent 5).

Through a series of higher education reforms, HEC tried to transform existing public universities according to a corporate governance model. However, this turned out to be difficult, because of the incongruence of the structure and culture of public universities with the purpose of reform.

Implementation of TTS differed between the natural and social sciences. One leader explained that the social sciences received less funding than the natural sciences because the former had fewer requirements for labs, materials, and equipment. He criticized social sciences faculty for not seeking funding and developing research projects. He said: 'Social Science faculty members did not have the energy to come forward with projects and write. I continuously phoned senior professors from social sciences urging them to send their research proposals. They never submitted a significant project in my tenure' (Case HEC: Informant 1). One leader also said that the leaders of the HEC were slightly biased in favor of the natural sciences. (Case HEC: Respondent 3). Another leader said that this was due to the background of the senior management of the HEC, who had trained and worked in the field of 'pure' sciences and engineering. He said: 'The Chairman was very biased towards disciplines of natural sciences. He forgot that Pakistan is struggling with terrorism, poverty, illiteracy, which are social and cultural issues. Physicists are not going to solve terrorism; the country needs a social scientist to develop indigenous solutions. You cannot have the same scale for social sciences and natural sciences. You need to look at social sciences from a different angle' (Case HEC: Informant 5).

Problems of Dual Reward Systems Another challenge the leaders of HEC faced was the way the TTS system was set up. Initially, HEC said that all faculty members should be eligible for the TTS system, even the established professors in the BPS system, meaning everyone should compete and show that they were competent researchers. On the one hand, TTS could seem attractive to senior professors if they were competent researchers, but it implied a high risk if they were not, and they could quite easily be bypassed by younger colleagues earning higher salaries. This led to many senior professors opting to stay with BSP as this seemed to secure them life-long tenure as civil servants, i.e. they were not easily persuaded to join TTS. The initial requirements of TTS later created confusion about tenure among university leaders and faculty members. 
The HEC put pressure on vice-chancellors of universities to recruit mostly $\mathrm{PhD}$ faculty to TTS, but many PhDs did not want to join TTS, creating an awkward situation for the vice-chancellors. One respondent shared his experience; 'I was VC of a remote University; The Chairman of HEC asked me to recruit all PhD faculty on TTS. I said that I wanted to run the university; people were not eager to join TTS'.

TTS was introduced as performance-based compensation for university faculty members. The resistance came from existing faculty, who were not willing to leave their permanent job, as stated above. The concept of performance-based compensation, where one needs to work for increments and promotion, was not compatible with the traditional culture in public universities. Faculty associations of older universities resisted implementation of TTS, as TTS offered contractual employment and required the academic staff to resign from a permanent job with all its perks. The view of the leaders in the HEC was that had TTS not been made mandatory for all faculty members in the selected universities, it would not have been implemented at all. The HEC chairman's response was that public universities were in disarray. Through TTS, the HEC had tried to develop a competitive environment where excellent academic staff would survive and weak ones would be removed. Initially, the scheme was concentrated in a few institutions, but gradually TTS was implemented across all public universities.

One leader considered BPS a major hindrance to the comprehensive implementation of TTS. He said: 'The BPS system was a complete disaster. The TTS system was suffering because the salary difference between TTS and BPS is getting less, and young teachers did not find TTS attractive at the Assistant Professor level. The TTS system is eroding presently, and this is something that needs to be addressed quickly by the government'. (Case HEC: Respondent 1). Another leader alleged that TTS 'polluted' the academic profession and provided teachers with an opportunity to make good money, thus shifting the focus of faculty to making more money by publishing research. He said: 'Teaching is not a profession for making money. Overall, TTS did not extend the boundaries of knowledge in public universities. TTS was not suitable for this country, people used it for their benefit' (Case HEC: Respondent 5).

Mostly, public universities were not ready to implement TTS, and various structural and cultural factors caused their faculty members to resist. The TTS guidelines did not fit the context of public universities in Pakistan - in fact they had been taken from the Tenure Track Statutes published in the University of New Mexico faculty handbook. The focus of the TTS scheme was on research, but at the time that TTS was initiated, many existing faculty members were not oriented towards publishing research. Implementation of TTS affected the culture of public universities. Power-based groups in universities sowed fear and mistrust in many faculty members to voice their concerns, and TTS is still struggling to put down roots in the university system. The chairman of HEC asserted, however, that Western university models were the best in the world, and that public universities in Pakistan could therefore improve their quality by emulating the Western model.

Some respondents in the HEC considered that the main problem of implementation arose from the existence of parallel TTS and BPS systems. BPS was the old reward system associated with the central pay structure of government civil servants. HEC advised universities to recruit faculty on TTS and gave existing faculty the option of a tenure-track appointment. A leader said: 'The BPS system was there; you could not 
force the existing teachers to abandon their permanent jobs. They might go to court and a court of law would not have allowed this to happen' (Case HEC: Respondent 5).

The HEC intended to replace BPS gradually in public universities. Therefore, it advised universities to recruit all recent PhDs as assistant professors on TTS. Despite HEC instructions, many universities kept recruiting faculty members on both systems. The Pakistani government revised national basic pay scales (BPS) annually, and this increased the salary of academics on BPS. TTS salaries were revised after three years, and there were delays in implementation. Consequently, the difference in salary between BPS and TTS at assistant professor level slowly became smaller. Many young faculty members on TTS were frustrated because this decreased the major attraction of TTS for young PhDs.

A respondent in the HEC said that TTS was not a suitable system for Pakistan; a large number of teachers did not have the skills or capabilities to be promoted on TTS. TTS put pressure on faculty members to publish, and some faculty members used shortcuts to meet requirements. Another respondent explained that some teachers 'teamed up' and put each other's names on publications to meet their tenure track requirements.

TTS was perceived as a contractual arrangement with a lengthy probation period. Faculty members compared TTS with the prevalent BPS system, which had a maximum probation period of two years for teachers to get permanent tenure. TTS had six years of probation and they needed to provide evidence of meeting their performance obligations during that period. Promotion and tenure were not guaranteed at the end of the tenure-track period.

To sum up, it appears that many people were not satisfied with the present status of TTS implementation in public universities. First, the continuation of BPS is a threat to the survival of TTS. Second, TTS compensation has not changed for the last four years. Third, the scheme was meant to attract new faculty, but it became more attractive for experienced professors, especially the productive ones. These professors, who had already qualified for pension benefits on BPS, considered TTS an attractive option for getting higher compensation.

\section{Implementation of TTS as Seen by the Provincial Higher Education Commission}

The PHEC was formed by a bill passed by the Punjab assembly on December 29, 2014. The PHEC was not directly involved in implementing TTS, but was able to closely observe its challenges. The following themes emerged during the interviews.

Role of the HEC in Implementing Higher Education Reforms The leaders of the PHEC thought the HEC had not been successful in phasing out BPS from public universities and making TTS a dominant performance and reward system for university teachers, i.e. there was a problem of parallel systems. BPS salaries increased annually in the federal budget, their pay scales were upgraded, and they had pension benefits. The HEC made incremental efforts to phase out BPS, but BPS was strong because of the historical traditions in public universities. Old universities adopted BPS in the 1970s and BPS was coupled with the pay scale of federal public servants, whose rights were 
strengthened over time. As the leaders of the HEC also pointed out, TTS and BPS were working in parallel in public universities. TTS did not gain the expected momentum and many new faculty members were inclined to join BPS, so the main problem of TTS was poor implementation in the sense that a competing system was not removed.

One leader identified a need for unified academic grades for public university teachers. He elaborated: 'Adoption of BPS systems in public universities was wrong from the beginning. Universities were autonomous bodies. They should have their own reward systems like private universities. New faculty with PhD degrees were coming on to this scheme, many of them wanted to join BPS after their one-year interim placement. People want to join BPS, as it provides pension benefits whereas TTS does not' (Case PHEC: Respondent 1).

The PHEC leaders alleged it was difficult for the HEC to handle all TTS faculty cases with few staff. Whereas this might be manageable during the initial phase of implementation, when there were few TTS faculty, as the number of potential TTS faculty members increased, the administrative capacity for processing cases could not cope. This caused long delays in the processing of TTS cases and handling grievances. The HEC wanted to increase the formal autonomy of public universities, but their procedures and structures undermined the real autonomy of public universities and were control-oriented. One leader said: 'HEC were not able to build the capacity of middle management in public universities to implement these programs. There was no Human Resource department in public universities' (Case PHEC: Informant 1). The problem was related to the compatibility of volume and frequency of reform programs with competencies of implementing managers and university infrastructure. The participant said that the leaders of the HEC involved themselves in trivial matters like degree verification, which could easily be delegated to the higher education institutions themselves.

After the establishment of the HEC, the number of higher education institutions increased. New universities were passing through a phase of transition, and their structure and culture were malleable, and leaders of these universities wanted to establish their legitimacy with the HEC. This was quite different from old universities with established norms, procedures, and culture, which resisted interventions in the reward system. This resistance increased as TTS potentially punctuated the equilibrium of rewards in universities, connected to the traditional path of the BPS system.

Concerning the difference in implementation of TTS between the natural and social sciences, one leader said: 'The design of research funding corresponded with natural science needs, and did not mention fieldwork, which is relevant to social sciences projects' (Case PHEC: Respondent 1). He added that the first chairman of HEC had a focus on technology and sciences: 'He had a positive bias towards technology and sciences. He still believed that the nation could not progress without progressing in technology and sciences. Leaders of HEC did not provide adequate funding for social science projects. They need to give importance to social science research'. He further asserted that the leaders of the HEC needed to shift their focus from generating lowquality scientific research in local universities to utilizing high-quality scientific research produced in the developed world. He said: 'We were not able to do proper scientific research. We did not have that kind of collaborations, network and resources. The best we can do is to apply advanced world research work. To see whether this research was applicable in our environment'. 
One of the participants said that some faculty members, like those in the humanities, the languages and the social sciences, were marginalized on TTS. The criterion for promotion on the tenure track - publishing in impact factor journals - were hard for social science disciplines. The careers of many faculty members get stuck due to this criterion of publishing in impact factor journals.

Effects of TTS in HEls Many young assistant professors at TTS considered senior professors to be significant beneficiaries of TTS. To qualify for pension benefit on BPS, one must serve the government for 25 years. Some senior professors switched to TTS, and they were evaluated for tenure after four years. Even if they failed to meet the TTS criteria, they got better compensation with TTS. They had a dual benefit - higher pay und TTS and the pension benefit of BPS. The HEC's motive for introducing TTS was to make the teaching profession attractive to young $\mathrm{PhDs}$, but the scheme became lucrative for professors to have the short-term incentive of TTS. Even if they failed on TTS, they would have the option of going back to BPS. This situation frustrated some young faculty members, who started their career with TTS. Young faculty on TTS compared their performance with the senior professors and pointed out that many professors had not had to go through the toil of the tenure track. This might frustrate and demotivate young faculty to continue with tenure track especially when the pay difference with their counterparts on BPS was not very large. The HEC kept on pushing the university management to recruit $\mathrm{PhD}$ faculty on TTS, but their vertical mobility on TTS was slow, owing to the slow progress of TTS implementation in public universities.

TTS also appears to be incongruous with the administrative structure of public universities. The HEC could have focused on capacity building of middle management of universities. There was no HR department in the universities. Initially, the HEC did not concentrate on building the capacity of the Registrar's office of public universities although this office was responsible for implementing TTS. Moreover, the HEC developed a complex process of filling out various forms for evaluation of TTS faculty members. Initially, the staff of the Registrar's office did not comprehend these cumbersome forms and procedures.

There were no extra incentives for women faculty during the implementation of TTS in public universities. Social and cultural values concerning the role of women in Pakistani society affect women's orientation towards work. The social dynamics have made female academic staff in the universities more risk averse. Therefore, few women decide to do PhDs and there are even fewer women on TTS. One leader explained: 'These were dynamics of our culture where you find more women at a lower position and fewer women at top positions. We were more comfortable to keep women at subordinate positions and were uncomfortable if women came to a leadership position. There was no bias in the scheme for favoring women' (Case PHEC: Respondent 2). He said that one needed to look at the reasons why there were few women on TTS in Pakistan. He said: 'The final appointment would be made by the selection committees, which often are chaired by the vice-chancellor. One could go and look into it more in-depth, why were women opting for the safe option and going for the BPS system rather than the tenure-track system or was there a bias in the system in the selection process, so both aspects needed to be looked at'. 
Some of the main differences in views on TTS between the HEC and the PHEC (exemplified by the views of their chairmen) are shown in Table 1,

\section{Discussion}

Seen from an instrumental perspective, the TTS reform scores relatively low on hierarchical control and rational calculation or analytical capacity (Lodge and Wegrich 2014). The HEC tried to control the reform from the top without too much involvement from the public universities and this turned out to be a big challenge. The

Table 1 Divergence in views on TTS in public universities, comparing the chairmen of HEC and PHEC

\begin{tabular}{|c|c|c|}
\hline & Chairman PHEC & Chairman HEC \\
\hline $\begin{array}{l}\text { Pre- } \\
\text { implementation } \\
\text { phase of TTS }\end{array}$ & $\begin{array}{l}\text { TTS imported from the US, like the semester } \\
\text { system. A prior report of the World Bank } \\
\text { influenced the creation of HEC in } 2002 \text {. }\end{array}$ & $\begin{array}{l}\text { This was all part of our indigenous } \\
\text { strategy for Pakistan, and it has } \\
\text { nothing to do with the World Bank } \\
\text { report about higher education in } \\
\text { developing countries. }\end{array}$ \\
\hline $\begin{array}{l}\text { Resistance } \\
\text { towards } \\
\text { implementation } \\
\text { of TTS }\end{array}$ & $\begin{array}{l}\text { There was no congruence of TTS with the } \\
\text { culture of universities. Many professors } \\
\text { protested against TTS. }\end{array}$ & $\begin{array}{l}\text { They were strongly opposed to the } \\
\text { tenure track system because it } \\
\text { exposed weaknesses for the majority } \\
\text { of teachers. }\end{array}$ \\
\hline Implementation & $\begin{array}{l}\text { TTS was not a suitable reward system for all } \\
\text { public universities; only a few universities } \\
\text { benefited from the scheme. The scheme } \\
\text { motivated senior professors to utilize the } \\
\text { short-term benefits of TTS. }\end{array}$ & $\begin{array}{l}\text { TTS was implemented fully in a few } \\
\text { universities and many other } \\
\text { universities implemented it in part. } \\
\text { The scheme was intended to attract } \\
\text { new faculty, but it was more } \\
\text { attractive for an experienced } \\
\text { professor in the initial years. } \\
\text { Improper implementation by public } \\
\text { universities threatened the existence } \\
\text { of the tenure track system. }\end{array}$ \\
\hline $\begin{array}{l}\text { Dual reward } \\
\text { system }\end{array}$ & $\begin{array}{l}\text { The reason people wanted to go back to BPS } \\
\text { was the absence of a Pension scheme in } \\
\text { TTS; moreover, their service on TTS does } \\
\text { not count for seniority. }\end{array}$ & $\begin{array}{l}\text { BPS system was a complete disaster. } \\
\text { TTS system was eroding, and this is } \\
\text { something that needs to be addressed } \\
\text { quickly by the government. }\end{array}$ \\
\hline Effects of TTS & $\begin{array}{l}\text { The focus of HEC leaders was on number of } \\
\text { publications. }\end{array}$ & $\begin{array}{l}\text { The main thing is to improve the } \\
\text { quality of universities, but there is } \\
\text { much resistance everywhere, and } \\
\text { this is the main challenge for leaders } \\
\text { in higher education. }\end{array}$ \\
\hline Focus of reforms & $\begin{array}{l}\text { HEC had overstretched itself by starting so } \\
\text { many new educational programs. HEC did } \\
\text { not focus on managerial competencies of } \\
\text { universities to implement reforms. }\end{array}$ & $\begin{array}{l}\text { Leaders of HEC need to focus on the } \\
\text { development of leaders at every level } \\
\text { in the higher education sector. }\end{array}$ \\
\hline $\begin{array}{l}\text { Effects of } 18 \text { th } \\
\text { amendment }\end{array}$ & $\begin{array}{l}\text { After the } 18 \text { th amendment, there was no federal } \\
\text { institution; everything was devolved to the } \\
\text { provinces. }\end{array}$ & $\begin{array}{l}\text { Creation of multiple regulatory bodies } \\
\text { at Federal and Provincial level was } \\
\text { going be a disaster if allowed to } \\
\text { happen because it introduced } \\
\text { multiple standards for institutions } \\
\text { and degrees. }\end{array}$ \\
\hline
\end{tabular}


HEC failed regarding analytical capacity, since its expertise was weak and the administration in the involved universities also had problems with expertise. Moreover, the HEC also failed regarding coordinating and regulatory capacity towards the universities, so they could not deliver the end product as planned. Therefore, the process had negotiation features (cf. March and Olsen 1983), between the HEC on the one hand, and the university administration and the academic staff on the other hand.

TTS did not fit with the structure of the older public universities in Pakistan (cf. Christensen et al. 2019). There was intense pressure from the HEC on public universities to adopt TTS, but there was ambiguity about how and when it should be implemented, which modified and delayed the process. These ambiguities meant that many implementation decisions were not standardized and often made on a case-bycase basis, depending on context, structure, and leadership of the organization.

According to the cultural perspective, and in particular historical institutionalism, 'path dependency' is essential, meaning informal norms and values from the early formative years of an institution determine the future path followed (Mahoney and Thelen 2010). TTS challenged the basic norm of long-term employment in BSP in public universities, and faculty were used to being promoted according to seniority and teaching performance, which for many did not correlate much with research performance (Cadez et al. 2017; González et al. 2012).

TTS evaluation was based mainly on the number of research publications. Teaching became a secondary activity, and the race began to publish more research papers, since this meant increments and promotion. TTS was monetized, and many faculty members expected to get money for every activity they performed. TTS is a performance-based, contractual employment system, and it brought job insecurity and a survival crisis for faculty members. What traditionally had been seen as culturally appropriate (cf. March 1994) changed rather dramatically. This created cultural resistance. Introducing change in a culture is a complex undertaking, and leaders were not able to control and anticipate the consequences of the reform and hence faced unintended consequences of TTS.

The HEC saw TTS as an opportunity to open the window to a more modern university system, but managed only partly to pry that window open (cf. Kingdon 1984). TTS can accordingly be seen as representing what was in some ways an unsuccessful 'punctuated equilibrium' of rewards in the public universities in Pakistan (cf. Baumgartner and Jones 1993). The increase in the salaries of BPS teachers was a step towards restoring this equilibrium when the reform met with resistance. TTS partially penetrated the culture of public universities and created a separate group of TTS faculty. This group was further reinforced by the recruitment of new faculty on TTS. Many faculty members got stuck at assistant professor level, and their cases did not move forward owing to various personal, structural and cultural factors. This led to frustration among TTS faculty.

The needs of the institution and the rights of the individual while implementing tenure track collided (Henningsson et al. 2018). The natural sciences faculty was more receptive to TTS owing to the congruence of their research tradition with the scheme. The social sciences and humanities faculties were more focused on teaching, and they found that the standards of TTS were not congruent with the content of their work. These changes in performance evaluation and rewards created anxiety among faculty members. This is similar to the experiences in some Chinese universities where the 
previous definition of academic work has been challenged, and many academics are not comfortable with TTS (Yan et al. 2013).

The HEC initiated various reforms during its first six years. These reforms created multiple ripples in the structure and culture of public universities. The internal environment of universities became more complex and hybrid (Christensen et al. 2019). Through TTS, the HEC tried to change the culture of public universities. It appears that TTS was implemented in haste, as various modalities of a change of culture were not anticipated. Changing a structure is easier than changing a culture, as it is difficult to express a culture's intangible features and tacit knowledge and link it to structural features (March 1994). TTS appeared decontextualized from the culture of old higher education institutions, whereas new universities were more receptive and more willing to adapt in implementing these reforms (cf. Brunsson and Olsen 1993).

Clark (1972) highlights the fact that universities are created as a combination of different structural and cultural factors, which gives them a unique identity. He argues that state-led reforms are not adequate to bring about real change in universities, as they ignore the dynamics and needs of individual universities (Clark 2004). The problem of implementation arises when change is considered as unidirectional and focused on design factors of programs from the top. Implementation of TTS could have been improved if the HEC had considered public universities as complex organizations with a dynamic relationship in the HEI organizational field. HEC leaders intended to bring about improvements in the performance of faculty in public universities through TTS, which was a radical change in academic employment. This change can be understood as 'complex ecology' (Gornitzka et al. 2007) with unanticipated consequences.

\section{Conclusion}

The basic story told in this study is one of an attempt at central control by a regulatory body to implement a higher education reform, namely, the TTS system. The attempt was partly thwarted by the lack of an overall masterplan for making this reform happen. The HEC lacked hierarchical authority and expertise and underestimated the problems of running two career systems at the same time, all factors that often undermine implementation (cf. Patashnik 2014). However, it also failed to show cultural sensitivity in not understanding that the reform represented a substantial break with the existing cultural norms of the public universities, especially the older ones (cf. Kingdon 1984).

The quality of higher education depends on the quality of faculty; therefore, many efforts to improve the quality of universities begin by analyzing faculty promotion and merit procedures (González et al. 2012). The HEC failed to bring about full and standardized implemention of TTS because its reactive approach resulted in a lack of consistency in implementation across different universities. There were delays and inconsistencies in the tenure decisions, and different characteristics of the universities and the academic staff. Moreover, the cultural resistance was compounded by the existing ambiguity, resulting in variations in implementation (cf. Patashnik 2014).

Multiple layers of regulatory bodies make the environment of Pakistani public universities complex and hence the reforms likewise. It is clear from our study that the leaders of the HEC made efforts to raise the quality of research and teaching in the higher education institutions of Pakistan. The leaders of PHEC told a different story of 
higher education reforms. They were trying to increase their influence in the higher education sector, while the chairman of the HEC said that duplication of regulatory bodies would create confusion among stakeholders and would damage the standards of higher education in Pakistan (see Table 1).

The HEC intended to replace BPS with TTS, but this did not happen, and both systems survived in public universities, which may be regarded as layering in an institutional sense (Mahoney and Thelen 2010). The survival of the two-tier system may depend on the formalization of the use of both systems and precise specification of the division of labor between two types of faculty (Park et al. 2011).

Pakistan's higher education system is experiencing a phase of transition, and interventions on a massive scale, like TTS, are affecting public universities. Regulatory bodies along with public universities must address the balance between expansion and quality, how to accomplish a smooth transition from the old system to the new system, how to balance Americanization and local educational, cultural values, and how to address the stress of inequity among academics.

Funding Open Access funding provided by University of Oslo (incl Oslo University Hospital).

\section{Appendix}

The following documents were analyzed for the study:

Table 2 Interviews with these leaders were conducted during the study.

\begin{tabular}{|c|c|}
\hline Name & Professional Title \\
\hline $\begin{array}{l}\text { Prof. Dr. Atta, ur } \\
\text { Rehman }\end{array}$ & Founding Chairman, Higher Education Commission. \\
\hline Dr Suhail Naqvi & $\begin{array}{l}\text { Former Executive Director HEC, } \\
\text { Vice-Chancellor, } \\
\text { Lahore University of Management Sciences }\end{array}$ \\
\hline Mr Muhammad Ismail & Consultant, Quality Assurance, Higher Education Commission, Pakistan \\
\hline Dr Mahmood Raza & $\begin{array}{l}\text { Former Advisor, Quality Assurance and Learning Innovation } \\
\text { Former Advisor, Human Resource Development } \\
\text { Former Advisor, Research and Development }\end{array}$ \\
\hline $\begin{array}{l}\text { Dr Mansoor Akbar } \\
\text { Kundi }\end{array}$ & $\begin{array}{l}\text { Former Executive Director, Higher Education Commission, Pakistan, } \\
\text { Former Vice-Chancellor, Gomal University, Baluchistan. }\end{array}$ \\
\hline Professor Dr. Nizam & $\begin{array}{l}\text { Chairman Provincial Higher Education Commission (PHEC), } \\
\text { Former Vice-Chancellor, University of Gujarat. }\end{array}$ \\
\hline Ms Zia Batool & $\begin{array}{l}\text { Director General-QA and Accreditation, } \\
\text { Punjab Higher Education Commission } \\
\text { Former Director-General, Quality Assurance, Higher Education Commission, } \\
\quad \text { Pakistan. }\end{array}$ \\
\hline
\end{tabular}


1. Higher Education in Developing Countries, a report by the World Bank published in 2002

2. Letter of Mr. Muhammad Ismail, Consultant Quality Assurance to All Vice Chancellors/ Rectors Public University, subject: Clarifications of TTS, dated April 12, 2016.

3. Model tenure track statutes, version 2, January 1, 2008.

4. Tenure track funds released to universities from 2005 to 2014.

5. Minutes of the meeting held to discuss issues \& challenges in the adoption/ implementation of the tenure track system on July 15, 2019.

6. Letter of Mr. Muhammad Ismail, Consultant Quality Assurance to All Vice Chancellors/ Rectors Public University, subject: Guidelines: Applying for initial appointment and promotion of TTS faculty, Jan 20, 2016

7. University of New Mexico, Faculty Handbook, February 16, 2017. Section B: Policy on Academic Freedom and Tenure

8. Higher education medium-term development framework -11 (MTDF II), 201115 issued by Higher Education Commission, Pakistan

9. Higher Education in Developing Countries, Peril and Promise, 2000, World Bank

10. Recurring Grant Released to Universities / Institutes / Centres from 2002 to 2016 issued by the Higher Education Commission

11. Report on Quality Assurance \& Accreditation Organization, Mechanisms and Practice, July 2016, Consultant, Prof. Dr. Riaz Hussain Qureshi, Higher Education Commission, Islamabad, Tertiary education support program.

12. Taskforce on the improvement of higher education in Pakistan, 2002, by Taskforce

13. Tenure track faculty strength, April 2016 issued by HEC, Pakistan

14. The Punjab Higher Education Commission Act 2015

Open Access This article is licensed under a Creative Commons Attribution 4.0 International License, which permits use, sharing, adaptation, distribution and reproduction in any medium or format, as long as you give appropriate credit to the original author(s) and the source, provide a link to the Creative Commons licence, and indicate if changes were made. The images or other third party material in this article are included in the article's Creative Commons licence, unless indicated otherwise in a credit line to the material. If material is not included in the article's Creative Commons licence and your intended use is not permitted by statutory regulation or exceeds the permitted use, you will need to obtain permission directly from the copyright holder. To view a copy of this licence, visit http://creativecommons.org/licenses/by/4.0/.

\section{References}

Baumgartner, F. R., \& Jones, B. D. (1993). Agendas and instability in American politics. Chicago: University of Chicago Press.

Beerkens, E. (2003). Globalization and higher education research. Journal of Studies in International Education, 7(2), 128-148.

Brunsson, N., \& Olsen, J. P. (1993). The reforming organization. London: Routledge.

Butler, J. (2019). Learning to lead: A discussion of development programs for academic leadership capability in Australian universities. Journal of higher education policy and management, 1-14. https://doi.org/10. 1080/1360080x.2019.1701855. 
Cadez, S., Dimovski, V., \& Groff, M. J. (2017). Research, teaching and performance evaluation in academia: The salience of quality. Studies in Higher Education, 42(8), 1455-1473.

Cantwell, B., \& Maldonado-Maldonado, A. (2009). Four stories: Confronting contemporary ideas about globalization and internationalization in higher education. Globalization, Societies and Education, 7(3), 289-306.

Christensen, T., \& Lægreid, P. (2007). The whole-of-government approach to public sector reform. Public Administration Review, 67(6), 1059-1066.

Christensen, T., Gornitzka, Å., \& Ramirez, F. O. (Eds.). (2019). Universities as agencies: Reputation and professionalization. Cham: Springer International Publishing.

Christensen, T., Lægreid, P., \& Røvik, K.A. (2020). Organization Theory and the Public Sector. New York: Routledge. $2^{\text {nd }}$ edition.

Clark, B. R. (1972). The organizational saga in higher education. Administrative Science Quarterly, 17(2), 178-184.

Clark, B. R. (2004). Delineating the character of the entrepreneurial university. Higher Education Policy, 17(4), 355-370.

Degn, L. (2014). Identity constructions and sense-making in higher education - A case study of Danish higher education department heads. Studies in Higher Education, 40(7), 1179-1193. https://doi.org/10.1080/ 03075079.2014 .881345 .

Egeberg, M. (2014). How bureaucratic structure matters: An organizational perspective. In B. G. Peters \& J. Pierre (Eds.), Handbook of public administration (2nd ed., pp. 77-87). London: Sage.

Ferlie, E., Musselin, C., \& Andresani, G. (2008). The steering of higher education systems: A public management perspective. Higher Education, 56(3), 325-348.

Gaus, N., Yunus, M., Karim, A., \& Sadia, H. (2018). The analysis of policy implementation models in higher education: The case study of Indonesia. Policy Studies, 40(1), 92-109. https://doi.org/10.1080/01442872. 2018.1539224.

González, C., Liu, Y., \& Shu, X. (2012). The faculty promotion and merit system in China and the United States: The cases of Wuhan University and the University of California. Research \& Occasional Paper Series: CSHE.13.12.

Gornitzka, Å., Maassen, P., Olsen, J. P., \& Stensaker, B. (2007). Europe of knowledge: Search for a new pact. In L. Zucker (Ed.), University dynamics and European integration (pp. 181-214). Dordrecht: Springer.

Harun, H., Wardhaningtyas, S., Khan, H. Z., An, Y., \& Masdar, R. (2019). Understanding the institutional challenges and impacts of higher education reforms in Indonesia. Public Money \& Management, 40(4), 307-315. https://doi.org/10.1080/09540962.2019.1627063.

Henningsson, M., Jörnesten, A., \& Geschwind, L. (2018). Translating tenure track into Swedish: Tensions when implementing an academic career system. Studies in Higher Education, 43(7), 1215-1226.

Huang, Y., Pang, S., \& Yu, S. (2016). Academic identities and university faculty responses to new managerialist reforms: Experiences from China. Studies in Higher Education, 43(1), 154-172. https:// doi.org/10.1080/03075079.2016.1157860.

Jeanes, E., Loacker, B., \& Śliwa, M. (2018). Complexities, challenges and implications of collaborative work within a regime of performance measurement: The case of management and organization studies. Studies in Higher Education, 44(9), 1539-1553. https://oi.org/10.1080/03075079.2018.1453793.

Khan, T. A., \& Nasira, J. (2011). Tenure-track system in higher education institutions of Pakistan: Prospects and challenges. Educational Research and Reviews, 6(9), 605-621.

Kingdon, J. (1984). Agendas, alternatives, and public policies. Boston: Little, Brown.

Kohtamäki, V. (2018). Academic leadership and university reform-guided management changes in Finland. Journal of Higher Education Policy and Management, 41(1), 70-85. https://doi.org/10.1080/1360080x. 2018.1553499.

Krücken, G. (2014). Higher education reforms and unintended consequences: A research agenda. Studies in Higher Education, 39(8), 1439-1450.

Lodge, M., \& Wegrich, K. (Eds.). (2014). The problem-solving capacity of the modern state. Oxford: Oxford University Press.

Ma, L., \& Christensen, T. (2018). Same bed, different dreams? Structural factors and leadership characteristics of central government agency reform in China. International Public Management Journal, 22(4), 643663. https://doi.org/10.1080/10967494.2018.1450311.

Mahoney, J., \& Thelen, K. A. (2010). Explaining institutional change. Ambiguity, agency and power. Cambridge: Cambridge University Press.

March, J. G. (1994). Primer on decision making: How decisions happen. New York: The Free Press.

March, J. G., \& Olsen, J. P. (1983). Organizing political life. What administrative reorganization tells us about government. American Political Science Review, 77(2), 281-297. 
Mohammadi, H., \& Mirzamohammadi, M. H. (2019). New public management (NPM) in the Iranian higher education; a moral analysis. Ethics and Education, 15(1), 113-133. https://doi.org/10.1080/17449642. 2019.1700453.

Olsen, J. P. (2009). Democratic government, institutional autonomy and the dynamics of change. Western European Politics, 32(3), 439-365.

Paradeise, C., Bleiklie, I., Enders, J., Goastellec, G., Michelsen, S., \& Reale, E. (2009). Reform policies and change processes in Europe. In J. Huisman (Ed.), International perspectives on the governance of higher education. Alternative frameworks for coordination (pp. 114-132). New York: Routledge.

Park, S., Sine, W. D., \& Tolbert, P. S. (2011). Professions, organizations, and institutions: Tenure Systems in Colleges and Universities. Work and Occupations, 38(3), 340-371.

Pashiardis, P., \& Brauckmann, S. (2018). New public Management in Education: A call for the Edupreneurial leader? Leadership and Policy in Schools, 18(3), 485-499. https://doi.org/10.1080/15700763.2018. 1475575.

Patashnik, E. M. (2014). Reforms at risk. What happens after major policy changes are enacted? Princeton and Oxford: Princeton University Press.

Pietilä, M. (2015). Tenure track career system as a strategic instrument for academic leaders. European Journal of Higher Education, 5(4), 371-387. https://doi.org/10.1080/21568235.2015.1046466.

Pietilä, M. (2017). Incentivising academics: Experiences and expectations of the tenure track in Finland. Studies in Higher Education, 44(6), 932-945. https://doi.org/10.1080/03075079.2017.1405250.

Pollitt, C., and G.Bouckaert. (2017). Public management reform: A comparative analysis - Into the age of austerity. Oxford: Oxford University press. $4^{\text {th }}$ edition.

Ramirez, F. O., \& Christensen, T. (2013). The formalization of the university: Rules, roots, and routes. Higher Education, 65(6), 695-708.

Selznick, P. (1957). Leadership in administration. New York: Harper \& Row.

Simon, H. A. (1957). Administrative behavior (4th ed.). New York: Macmillan.

Söderlind, J., \& Geschwind, L. (2019). Making sense of academic work: The influence of performance measurement in Swedish universities. Policy Reviews in Higher Education, 3(1), 75-93. https://doi.org/ 10.1080/23322969.2018.1564354.

Tierney, W. G. (2014). Higher education research, policy, and the challenges of reform. Studies in Higher Education, 39(8), 1417-1427.

Tight, M. (2007). Bridging the divide: A comparative analysis of articles in higher education journals published inside and outside North America. Higher Education, 53(2), 235-253.

Yan, L., Jessica, L., \& Sun, Y. (2013). Young faculty job perceptions in the midst of Chinese higher education reform: The case of Zhejiang University. Asia Pacific Journal of Education, 33(3), 273-294.

Publisher's Note Springer Nature remains neutral with regard to jurisdictional claims in published maps and institutional affiliations.

Tayyeb Ali Khan did his PhD (Management) from Institute of Administrative Sciences (IAS), University of the Punjab. During his $\mathrm{PhD}$, he studied content, process and implementation of new performance and reward system for academics in public universities of Pakistan. He did his Masters in Public Administration, and Master of Philosophy in Management from the same university. His area of research is Higher Education Management for the last 12 years. Presently, he is working as Assistant Professor at IAS, University of the Punjab. He has about 20 years of teaching, research, and professional work experience in public universities of Pakistan.

Tom Christensen is Professor Emeritus in Public Administration and Policy, Department of Political Science, University of Oslo. He is also Visiting Professor at School of Public Administration and Policy, Renmin University and Distinguished Visiting Professor at School of Public Policy and Management, Tsinghua University. Based in organization theory, he works in the field of comparative public administration and reforms, and he has published extensively in the major journals in the field, covering a variety of public sectors. 